\section{Vis attractiva and vis nervosa}

saac Newton (1642-1727) transformed our understanding of the physical world by introducing the concept of an attractive force, vis attractiva, or gravity, and applying mathematical principles for the discovery of natural laws. In the last three centuries this Newtonian approach has gradually led to our modern understanding of the Universe, especially through the work of Michael Faraday (1791-1867) and Robert Clerk Maxwell (1831-1879) in the $19^{\text {th }}$ century and Einstein (18791955) in the $20^{\text {th }}$ century. ${ }^{1}$

Likewise, adopting a similar Newtonian strategy, the proposal of a nervous force or vis nervosa by Juri (George) Prochaska (1749-1820), Professor of "Anatomie, Physiologie, und Augenarzneykunde" in Vienna, has gradually transformed our understanding of the nervous system. ${ }^{2}$ Prochaska was a pioneer in neurophysiology and strove to make physiology a branch of experimental physics. ${ }^{3} \mathrm{He}$ describes his concept of vis nervosa in his "Dissertation on the functions of the nervous system", which was published originally in Latin and translated into English by Thomas Laycock on behalf of the Sydenham Society in $1851 .^{2} \mathrm{He}$ emphasises that he is abandoning the Cartesian method of philosophising and taking up the excellent Newtonian inductive method:

\begin{abstract}
"Newton designated the mysterious cause of physical attraction by the term of vis attractiva, observed and arranged its effects, and discovered the laws of motion; and thus it is necessary to act with reference to the functions of the nervous system: we will term the cause latent in the pulp of the nerves, producing its effects, and not as yet ascertained, the vis nervosa: we will arrange its observed effects, which are the functions of the nervous system, and discover its laws".
\end{abstract}

The term vis nervosa was first coined by Albrecht von Haller (1708-1777) to represent the agent long previously thought to be a nervous fluid or "animal spirits" flowing in hollow nerves from the brain and employed in exciting muscular contraction. ${ }^{4}$ Prochaska instead invested the phrase with new meaning for the latent force within nerves "by which the nervous system is rendered fit for the performance of its functions". As the invisible element "is as mysterious and unknown as the vis attractiva of matter, it seems to me that it may be termed with propriety the vis nervosa". ${ }^{2}$

Prochaska describes the general properties of the vis nervosa and introduces another novel concept, that a stimulus is necessary for the action of the vis nervosa. The vis nervosa

"is not the chief and sole cause that excites the actions of the nervous system, but is ever latent, and exists as a predisposing cause, until another exciting cause, which we term stimulus, is brought to bear".

If the stimulus is removed the vis nervosa ceases to act, or if re-applied it acts again.

He distinguished two broad categories of stimuli, those of the body (mechanical) and those of the mind. There is a proportionate, mathematical relationship between the stimulus and the vis nervosa. Thus a powerful stimulus and less active vis nervosa may equate with a weak stimulus and a more active vis nervosa. Various stimuli may have local or general effects in the nervous system, the latter especially if stimuli are powerful and prolonged, when they may overflow through reflex activity into motor effects-for example, movements or convulsions, another new concept. Likewise the vis nervosa may vary in degree locally within the nervous system and more generally according to differences in age, sex, temperament, climate, health, or disease.

The vis nervosa is divisible and exists in the nerves independently of the brain. It remains in each portion of a bisected nerve, including nerves that were never connected with the brain. It can still be detected to a slight degree soon after apparent death, when the heart or muscle may be unexpectedly irritated. It may be diminished by opium. Finally it may be modified by habit and some individuals show unusual idiosyncratic responses to stimuli in health or disease and also in pregnancy.

Prochaska's concept of vis nervosa was taken up by Robert Bentley Todd (18091860), Professor of Physiology and Morbid Anatomy at King's College, London. Todd was influenced by his contemporary, Michael Faraday (17911867), Professor of Chemistry at the Royal Institution in London, who Todd knew and met when Faraday was laying the foundations of our modern understanding of electromagnetism. ${ }^{5}$ Todd applied Faraday's concepts to the nervous system and viewed Prochaska's vis nervosa as a polar force as defined by Faraday. Todd used the terms vis nervosa, nervous force, nervous power and nervous energy interchangeably but proposed that "nervous polarity" was the most appropriate term as it was expressive of the nature of this force. ${ }^{36}$ At this time there was also much interest in the concept of "animal electricity" following the observations of Galvani and his dispute with Volta. ${ }^{4}{ }^{6}$ From their own and other studies, including those in

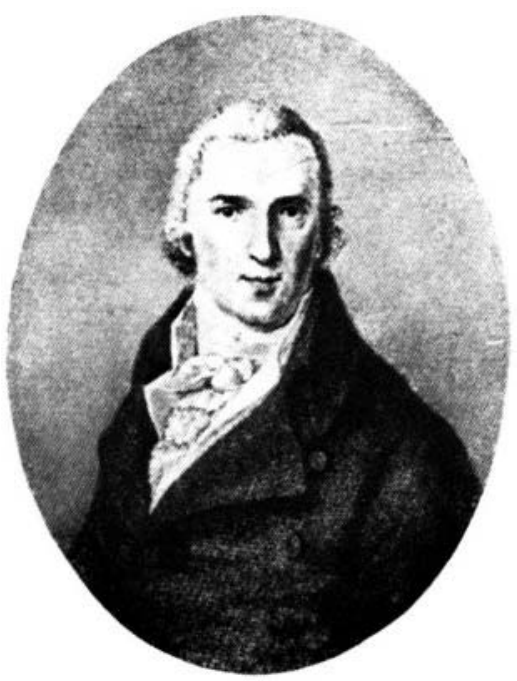

Figure 1 Juri Prochaska, who developed the concept of vis nervosa or nervous force influenced by Isaac Newton's discoveries.

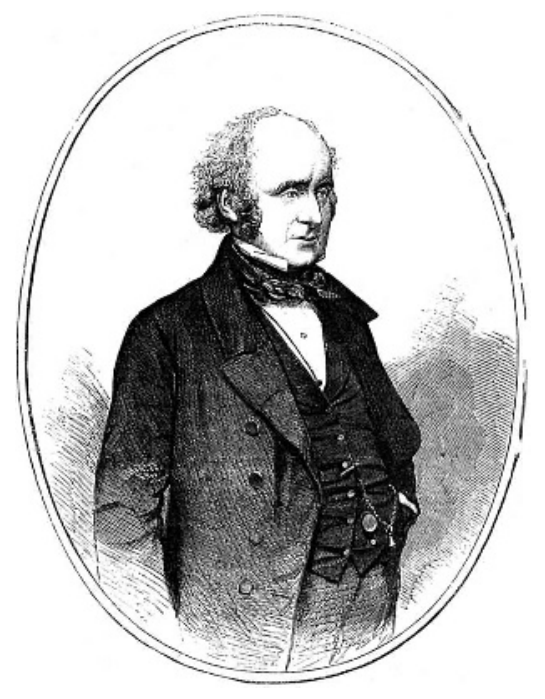

Figure 2 Robert Bentley Todd, who further developed the concept of nervous force or nervous polarity, influenced by Michael Faraday's discoveries. 
electric fish, Todd and Faraday viewed nervous polarity as analogous to but not identical with electricity, perhaps a higher form of interchangeable energy. ${ }^{6}$ Todd used Faraday's newly discovered magneto-electric machine to induce seizures in rabbits to develop his concept of nervous polarity and a radically new electrical theory of epilepsy incorporating Faraday's concept of "disruptive discharge". ${ }^{5}$

Todd was also a pioneer microscopist. He saw that for a nervous "fibre" to maintain its vis nervosa or nervous polarity it must retain its connection with a nervous "vesicular" centre. Indeed he was the first to perceive each nerve vesicle and its related fibres-that is, neurone in later terminology, as a distinct entity for the generation of nervous polarity and its transmission in the white nerve fibres throughout the nervous system by as yet unknown molecular mechanisms responsible for the rapid polarisation of neighbouring particles. ${ }^{67}$
It was just over a century later that Hodgkin and Huxley won the Nobel Prize for their discovery of the ionic basis of Prochaska's nervous force and Todd's nervous polarity. ${ }^{8}$ Interestingly it was Faraday's predecessor and mentor, Sir Humphry Davy (1777-1829), who discovered sodium, potassium, chloride, calcium, and magnesium among other elements, by developing the science of electrolysis using Volta's battery. ${ }^{59}$ Today, with the help of our own vis nervosa and through cerebral mechanisms that remain as mysterious to us as did vis attractiva to Newton and vis nervosa/nervous polarity to Prochaska and Todd, we continue to struggle to understand the nature and influence of both forces within the Universe, including our very complex brains.

E H Reynolds Institute of Epileptology, Weston Education Centre, King's College, Denmark Hill Campus; Cutcombe Road, London SE5 6PJ; reynolds@buckles.u-net.com

\section{References}

1 Thomas JM. Michael Faraday and the Royal Institution. Bristol: Adam Hilger, 1991.

2 Prochaska G. Dissertation on the functions of the nervous system. In: Laycock T (translator and editor): Principles of physiology by John Augustus Unzer and a dissertation on the functions of the nervous system by George Prochaska. London: The Sydenham Society, 1851.

3 Todd RB. Nervous system. In: Todd RB, ed. Cyclopaedia of anatomy and physiology. London: Longman, Brown, Green, Longmans, \& Roberts, 1839-1847, 1847;3:585-723G.

4 Clower WT. The transition from animal spirits to animal electricity:a neuroscience paradigm shift. $J$ Hist Neurosci 1998; 7:201-18.

5 Reynolds EH. Todd, Faraday, and the electrical basis of epilepsy. Epilepsia 2004:45:985-92.

6 Reynolds EH. Todd, Faraday and the electrical basis of brain activity. Lancet Neurology 2004:3:557-63.

7 Todd RB, Bowman W. The physiological anatomy and physiology of man. 2 volumes. London Parker, 1845-1856.

8 Hodgkin AL, Huxley AF. A quantitive description of membrane current and its application to conduction and excitation in nerve. J Physiol 1952;177:500-44.

9 Knight D. Humphry Davy: Science and power. Cambridge, Cambridge University Press, 1996.

\section{bmjupdates+}

bmiupdates+ is a unique and free alerting service, designed to keep you up to date with the medical literature that is truly important to your practice.

bmiupdates+ will alert you to important new research and will provide you with the best new evidence concerning important advances in health care, tailored to your medical interests and time demands.

\section{Where does the information come from?}

bmjupdates+ applies an expert critical appraisal filter to over 100 top medical journals A panel of over 2000 physicians find the few 'must read' studies for each area of clinical interest

Sign up to receive your tailored email alerts, searching access and more... www.bmjupdates.com 